\title{
What organizational steps are necessary, to successfully establish a culture of open innovation in the company?
}

\author{
Marco Pister * \\ SEEBURGER AG, Edisonstr. 1, 75015 Bretten, Germany
}

\begin{abstract}
This paper investigates in open innovation, organizational culture, internal and external collaboration and the steps which are necessary to establish a culture of open innovation in the company. Open innovation is one of the most relevant topic in research and development. The research results concentrate on, how leaders can shape a corporate culture and environment in which open innovation processes are embrace and can implemented successfully. Innovation processes have a high risk factor. This is precisely why it is crucial to create a corporate culture that is open to failure and also accepts less successful attempts. The attitude of the management is one of many key factors.
\end{abstract}

\section{Introduction}

\subsection{Topicality and Relevance}

The contemporary business environment is increasingly shaped by the need for innovative products and services, which is accentuated by Edelbroek, Peters, and Blomme [7], who argue that typical life cycles of products become shorter, thus amplifying the need for companies to innovate more frequently. Innovation itself is therein characterized as a complex process: "Innovation can be viewed as an organizational process, often initiated by organizations' internal Research and Development departments, which comprises three main elements: idea generation, (...) idea promotion, (...) and idea realization" [7].

This trend towards an increased necessity for innovation is - among other reasons - being driven by fast developments in the technology sector, where new possibilities in regard to technological solutions increasingly offer new chances for companies [21]. Kratzer, Meissner, and Roud [12] argue in these regards that while the need for stronger innovation is evident and a business imperative, it should not be forgotten that innovation and the underlying processes always bear the threat of failure. This seems especially true for disruptive technologies and associated products and services - while such approaches might be deemed drivers of the market, they always bear the risk for companies to experience failures with accordingly negative consequences that have to be viewed throughout the lens of corporate risk management. However, the authors further argue that the solution to this

\footnotetext{
*2marco.pister@web.de
} 
challenge does not lie in avoiding innovation, but rather in finding strategies to minimize the associated risk. One of these strategies lies in what Müller and Thoring [13] describe as failing early: As typically costs, and thus the risk, of innovation processes scale drastically with time, the authors argue that it is imperative for innovators to achieve the critical failure stage at an early point in the development while the investment is still comparatively low.

Failures in innovation processes typically arise from a lack of acceptance on the market [13]. As new products always bear the risk of not meeting market demands and thus failing financially, the authors argue that it is crucial to not await the fully finished and presentable product before approaching potential customers, but to approach the potential market already at early stages of development, in order to make sure that the market demands are understood correctly and are thus met. This early evaluation, the authors argue, allows companies to minimize the chances of failure while still at a low-investment stage. This strategy, Müller and Thoring [13] showcase, can be described as one aspect of open innovation processes, which are considered to be a contemporary and successful way to foster corporate innovation. This paper seeks to assess in how far such strategies are dependent on company internal factors and how leadership processes can influence a company's ability to utilize open innovation.

\subsection{Research Statement and Research Question}

The present work, as described, builds on the state of research regarding open innovation processes and their relevance for successful product and service development within the contemporary business environment. While the general feasibility of such an approach to innovation seems well established within the existing scientific literature on the topic, it seems unclear how organizations can achieve a working environment in which open innovation processes can easily be implemented. This work acknowledges that leaders play an important role in creating such an environment, while arguing that the connection between leadership, corporate culture, and success in implementing open innovation processes seems less well established. While leadership can also be discussed throughout the lens of thought leadership, the focus within this publication lies on the application of leadership to the field of internal communication, where leaders create the necessary conditions in which open innovation strategies and subsequently innovation success can prosper. The leading research question of this publication on leadership, culture, and innovation, thus, is as follows: How can leaders shape a corporate culture and environment in which open innovation processes are embraced and can be implemented successfully?

\section{Open Innovation - Approaches, Benefits, and Challenges}

\subsection{Early Developments and Comparison to Other Innovation Approaches}

Open innovation is one of the most relevant topics in research and development. The idea behind the concept of open, and thus collaborative, innovation is that it is no longer possible for a company to innovate in isolation from its environment [13 \& 5]. In order to remain competitive, it is necessary to draw on different partners and resources and thus to open up one's own boundaries, both in relation to potential competitors and to representatives of the market in which one operates. Following these reflections, Chesbrough [5] formulated an attempt to define what Open Innovation is: it is a paradigm 
according to which companies should draw on both external and internal ideas and approaches and pave the way to the market, including in cooperation with partners.

While much of the scientific literature on Open Innovation focuses on large, multinational companies, findings such as those of van de Vrande, de Jong, Vanhaverbeke, and de Rochemont [19] show that the topic is also of increasing relevance to small and mediumsized companies: According to the Dutch study, medium-sized companies in particular were very active in the area of Open Innovation, primarily following the motive of being competitive in this way. The authors argue that for younger, less established companies in particular, open innovation can also pose a threat in terms of corporate culture. Opening up to cooperation with other companies and even competitors could lead to drastic changes within the corporate and communication culture and even to an exodus of employees.

This in turn ties in with the assumptions of Jabbour and Santos [11] and makes it clear why HR management (HRM) is so important for innovation projects. HRM can, on the one hand, serve as a safeguard against such potentially harmful influences and, on the other hand, lead to an open corporate culture that welcomes innovation. In terms of open innovation, the aim is to create a corporate culture that is open to collaborative working and fosters a positive culture of error.

\subsection{Leadership and Open Innovation - Chances and Challenges}

Open innovation communities, as Fleming and Waguespack [8] describe them, in many cases lack the structure of more classical corporate settings and rely heavily on implicit types of collaboration. This seems especially true for the more open formats which only partially are driven by classical leadership, as the participation is in many cases not described as mandatory: "leadership in such communities depends more on the trust and mobilization of peers than on approval of superiors. To wit, members cannot be fired or forced to participate in any activity, nor can they be compelled to pay attention to any other member" [8].However, as the authors further argue, this implicit setting with a less direct approach to leadership does not negate the necessity of strategic leadership, rather, it elevates the demands for leaders. As they can typically not rely on hierarchical and organizational structures only, Fleming and Waguespack [8] argue, leaders have to increasingly rely on their persuasive capabilities or, as Bass and Avolio [3] explain, the transformative power of transformational leadership. Such a leadership approach is characterized by the authors as one that relies less on the transactional nature - thus, on rewarding behavior throughout corporate structures and processes -, and rather on enabling and motivating employees. Transformational leaders, therefore, typically aim to shape an environment and a relationship between the organization and its employees that leads to employees being intrinsically motivated to work for the company and to follow its goals.

This is also acknowledged for the field of open innovation, where authors such as Edelbroek, Peters, and Blomme [7] showcase the influence that transformational leadership can have on the quality of the outcome of open innovation processes. The authors argue that transformational leadership is a feasible tool for leaders to foster the organizational engagement of their employees. As transformational leadership aims to foster such commitment and - as studies cited by the authors indicate - does so successfully, it can be shown that transformational leaders can increase pro-active and more innovative behavior of their employees. Also, by developing a higher level of commitment and experiencing emotional support through transformational leaders, employees tend to experience stronger self-efficacy, which in turn can influence their creativity- and innovation-related behavior positively. The authors were also able to showcase this by utilizing an empirical study where they assessed how increased organizational commitment can actually influence the quality of open innovation processes. In a similar vein, Naqshbandi, Tabche, and 
Choudhary [14] established a significant connection between the usage of transformational and enabling leadership styles and open innovation.

\section{Corporate Culture}

\subsection{Corporate Culture and Leadership}

Corporate culture is described by Appelbaum et al. [1] as a collection of characteristics of an organization that contribute to the organization's overall mood or environment, implying that it is a highly contextual concept.

In this regard, the scholars equate an organization's organizational culture to a person's personality, in which personality psychologists such as Goodman, Disabato, and Kashdan [9] summarize a collection of beliefs, interaction and communication patterns, and fundamental personality characteristics for organizations and their culture, which Denison [6] describes similarly.

Corporate culture is increasingly playing a supporting role in organizations, as summarized by Ramdhani, Rahmdhani, and Ainisyifa [15] "Corporate culture is one of a determinant factor in enhancing to achievement of organizational goals and objectives. Corporate culture as an important aspect of not only in organizational behavior but also as a tool in understanding how organizations function".

This aspect of contemporary entrepreneurship is thus critical not just for practice but also for scientific observation, which is increasingly concerned with the question of how culture itself has a formative effect on various aspects of corporate performance on the one hand, and how culture can be shaped in the context of the corporate vision on the other (as will be shown in the following sections).

Guiso, Sapienza, and Zingales [10] use Goldman Sachs and a quote by its Vice President, Greg Smith, as a well-known example of how the public perceives and values business cultures. According to the writers, the latter said in an interview that he has always believed that the company's culture is a major factor in its growth. He explains the dominant culture in this regard as "revolved around teamwork, integrity, a spirit of humility, and always doing right by our clients" [10].

However, the writers assert that this corporate culture, which is defined by sustainability and social responsibility, cannot be sustained in the long run, demonstrating that corporate cultures need appropriate treatment.

Corporate culture may be shaped by a variety of factors, but writers such as Bolton, Brunnermeier, and Veldkamp [4]) emphasize the managers' actions and describe how managers may significantly contribute to defining an organization's culture through their engagement and value exchange.

Corporate culture, in any case, is critical for managers, as shown by Syafii, Thoyib, and Nimran [4], who demonstrate that corporate culture is a critical variable that both represents and affects manager behavior. Transformational leadership can be described as leading in this way [2] This leadership approach seeks to achieve the best possible fit between organizational ideals, visions, and priorities and the desires and motivations of workers. The establishment and preservation of a complementary organizational culture is represented in this context as a mediating force between leadership and entrepreneurial results, as shown by the aspect of creative power [18].

\subsection{Openness and Innovation}


The importance of corporate culture on the topic of (open) innovation is also highlighted by Kratzer, Meissner, and Roud [12]. Especially given the inherently risky nature of innovation processes, the authors explain that it is crucial to create a corporate culture open to failure and accepting of less successful trials: "For all of the features, the management's attitude towards risky innovation projects is one of many key factors. However, the attitude towards risk is especially important as it correlates strongly with the central features of the innovation concept, namely the newness of the solutions and the willingness to change" [12]. Thus, the authors explain both on theoretical frameworks and their own empirical data that an open corporate culture and collaboration style does not only influence employees' willingness to participate in such endeavors but also favorably shapes the success of such projects. This is confirmed by a recent study by Yun, Zhao, Jung, \& Yigitcanclar [22], who argue that corporate culture can in general be considered to be among the driving forces behind innovation: "Innovation culture, which is a kind of static and open innovation culture, is a transdisciplinary culture with the aim to pragmatically integrate anything desirable, necessary, useful, feasible, and appropriate; innovation culture is mainly considered to be an aspect of organizational culture, where the societal innovation culture always sets the context" [22].

\section{Discussion}

\subsection{Critical Discussion and Limitations}

While the present work aimed to establish the connection between corporate leadership, corporate culture, and success in the implementation of open innovation strategies, the approach can only be discussed as exploratory in nature. Building on the contemporary state of research - as described throughout the previous sections of this publication -, the author managed to showcase in how far leaders can use their communication approaches to shape an open-minded corporate culture which, subsequently, should allow for the usage of open innovation. At the same time, it was highlighted that such strategies do not only offer chances on a competitive market [16] but can also be seen as challenging in regard to their implementation: one of the core issues named in this context is the changing role of employees within companies. Especially the networking-aspect arising from the intensified collaboration between clients and internal employees is described here as a challenge for many: While more classical ways of collaboration between companies and their clients saw interaction points mostly in sales teams or key account management, the contemporary approach sees increasing collaboration also between teams of researchers. While this challenge is discussed within this work, it also needs to be concluded that open innovation does not only have a communication or collaboration component but also one that focuses on the way mistakes and failures are addressed within the company. As the introduction of this paper with regard to Edelbroek, Peters, and Blomme [7] stated, in the business environment described throughout this publication, it seems necessary to acknowledge that innovation without failure seems impossible, and indeed, a majority of innovation processes do not turn out to be successful. Thus, authors such as Yun, Zhao, Jung, and Yigitcanlar [22] argue that it needs to be one of the key characteristics of the corporate culture to allow and embrace mistakes and successless developments as a natural aspect of innovation, especially in highly disruptive fields. Thus, leaders are recommended to shape their communication and attitude in a forgiving and embracing way. While the present work was able to establish this general framework, it remains unclear with which tools and strategies these goals can be achieved. This leads back to the explorative nature of the work: Derived from the state of research, it can be summarized that a relationship between the relevant 
variables seems to exist. However, the complexity of the topic and the sheer amount of potentially influencing factors and variables highlights the necessity for further empirical work on the topic. This is perceived as critical in light of the existing literature which mostly points a theoretical perspective on the topic. Over the analysis of the recent scientific work on the topic, a lack of systematic reviews or meta-analyses was identified, which might be a feasible way to foster understanding on the topic. As it was argued within the introduction of this topic, it seems to be clear that open innovation processes are a legitimate tool to foster innovation success, and leaders can create conditions in which such processes prosper. However, further clarification seems necessary on the exact nature of the influence of leadership, subsequent organizational culture, and open innovation success.

Concludingly, however, it can be summarized that leaders have a twofold influence: First, in an optimal scenario, they enable and motivate their employees to go above and beyond the necessary requirements and to believe in themselves. Second, they shape a corporate culture in which innovation can grow.

\subsection{Outlook}

As Yun, Won, and Park [21] argue, open innovation processes might gain further relevance in an increasingly competitive market environment shaped by faster product life cycles. Thus, it can be assumed that it will remain a core challenge for leaders to create the right conditions for further implementation of suitable approaches. At the same time, however, leaders worldwide are combating a disruptive change in organizational collaboration brought on by the recent COVID-19 pandemic: As the crisis continues to influence societal and business life, the typical mode of collaboration in many companies changed in a significant way, as Waizenegger, McKenna, Cai, and Bendz [20] summarize with regard to the increasing usage of tele-work tools and virtual meetings. While open innovation is a type of R\&D focusing heavily on interactive formats and collaboration between individuals, this pandemic-induced change might also affect the usage of such innovation strategies and will require leaders to find ways to lead the corporate cultures necessary for successful innovation into an increasingly digitalized work environment. While the work environment shifts, the challenges may continue to grow. This also is highlighted by Fleming and Waguespack [8], who concludingly highlight that findings from classical, i.e., physical, interactions in the field cannot necessarily be applied to digitalized communication: "Caution should also be exercised before generalizing the results to all open innovation communities, particularly those that lack physical interaction” [8].

\section{References}

1. Appelbaum, S., Bartolomucci, N., Beaumier, E., Boulanger, J., Corrigan, R., Dore, I., ... \& Serroni, C., Organizational citizenship behavior: a case study of culture, leadership and trust. Management decision, 42(1), 13-40 (2004)

2. Bass, B. M., \& Avolio, B. J. (Eds.), Improving organizational effectiveness through transformational leadership. sage. (1994)

3. Bass, B. M., \& Riggio, R. E., The transformational model of leadership. Leading organizations: Perspectives for a new era, 2, 76-86 (2010)

4. Bolton, P., Brunnermeier, M. K., \& Veldkamp, L., Leadership, coordination, and corporate culture. Review of Economic Studies, 80(2), 512-537 (2013)

5. Chesbrough, H. W., Open innovation: The new imperative for creating and profiting from technology. Harvard Business Press (2003)

6. Denison, D. R., Bringing corporate culture to the bottom line. Organizational dynamics, 13(2), 5-22 (1984) 
7. Edelbroek, R., Peters, P., \& Blomme, R. J., Engaging in open innovation: The mediating role of work engagement in the relationship between transformational and transactional leadership and the quality of the open innovation process as perceived by employees. Journal of General Management, 45(1), 5-17 (2019)

8. Fleming, L., \& Waguespack, D. M. (2007). Brokerage, boundary spanning, and leadership in open innovation communities. Organization science, 18(2), 165-180.

9. Goodman, F. R., Disabato, D. J., \& Kashdan, T. B., Integrating psychological strengths under the umbrella of personality science: Rethinking the definition, measurement, and modification of strengths. The Journal of Positive Psychology, 14(1), 61-67 (2019)

10. Guiso, L., Sapienza, P., \& Zingales, L., The value of corporate culture. Journal of Financial Economics, 117(1), 60-76 (2015)

11. Jabbour, C. J. C., \& Santos, F. C. A., The central role of human resource management in the search for sustainable organizations. The International Journal of Human Resource Management, 19(12), 2133-2154 (2008)

12. Kratzer, J., Meissner, D., \& Roud, V., Open innovation and company culture: Internal openness makes the difference. Technological Forecasting and Social Change, 119, 128-138. doi:10.1016/j.techfore.2017.03.022 (2017)

13. Müller, R. M., \& Thoring, K., Design thinking vs. lean startup: A comparison of two user-driven innovation strategies. Leading through design, 151, 91-106 (2012)

14. Naqshbandi, M. M., Tabche, I., \& Choudhary, N., Managing open innovation. Management Decision, 57(3), 703-723 (2019)

15. Ramdhani, A., Ramdhani, M. A., \& Ainissyifa, H., Conceptual framework of corporate culture influenced on employees' commitment to organization. International Business Management, 11(3), 826-830 (2017)

16. Rauter, R., Globocnik, D., Perl-Vorbach, E., \& Baumgartner, R. J., Open innovation and its effects on economic and sustainability innovation performance. Journal of Innovation \& Knowledge, 4(4), 226-233 (2019)

17. Shafie, S. B., Siti-Nabiha, A. K., \& Tan, C. L., ORGANIZATIONAL CULTURE, TRANSFORMATIONAL LEADERSHIP AND PRODUCT INNOVATION: A CONCEPTUAL REVIEW. International Journal of Organizational Innovation, 7, 30-43 (2014)

18. Syafii, L. I., Thoyib, A., \& Nimran, U., The role of corporate culture and employee motivation as a mediating variable of leadership style related with the employee performance (studies in Perum Perhutani). Procedia-Social and Behavioral Sciences, 211, 1142-1147 (2015)

19. Van de Vrande, V., De Jong, J. P., Vanhaverbeke, W., \& De Rochemont, M., Open innovation in SMEs: Trends, motives and management challenges. Technovation, 29(6-7), 423-437 (2009)

20. Waizenegger, L., McKenna, B., Cai, W., \& Bendz, T., An affordance perspective of team collaboration and enforced working from home during COVID-19. European Journal of Information Systems, 29(4), 429-442 (2020)

21. Yun, J. J., Won, D., \& Park, K., Entrepreneurial cyclical dynamics of open innovation. Journal of Evolutionary Economics, 28(5), 1151-1174 (2018)

22. Yun, J. J., Zhao, X., Jung, K., \& Yigitcanlar, T., The culture for open innovation dynamics. Sustainability, 12, 1-21 (2020) 